\title{
Is a profile in social software a learning e-portfolio? If not, could any benefits be gained from linking the two?
}

\author{
Lise Agerbak, Institute of Literature, Media and Cultural Studies, \\ University of Southern Denmark
}

This article compares learning e-portfolios with profiles in social software environments (like Facebook, MySpace and LinkedIn). The similarities are that both are forums for self representation. The difference between the two is that the self is represented for different purposes. In the social profile the purpose is to be one among a crowd (whether this crowd is a group of friends or a group of professionals). You can express yourself only through the ways the software deems important. In e-portfolios the purpose is to "show and tell" competences and growth - and to express this in a free text and visual fashion. This is difficult using existing social software. In an e-portfolio the way you represent yourself shows a communicative competence.

Should educational institutions then ignore or even ban the use of profiles? The article suggests a way in which they might benefit from a double strategy: Firstly to enable and empower the pupils/students as learners through the employment of a programme of learning e-portfolios (Qvortrup, Lund, Ellmin). In the literature on e-portfolios one of the main conclusions is that reflecting on learning enables the learner to understand and appreciate his or her own competences. Secondly, to enable the student to benefit from social software's ability to establish relations - and to focus on the competence of creating and maintaining professional relationships.

This strategy is beneficial because it addresses a problem often encountered when employing a program of e-portfolios. The students feel no "inner need" to fill them out. They do not view the e-portfolio as a means of persuading their readers - possibly because they are, through the e-portfolio, talking to an unknown audience. Here the e-portfolio is discussed as rhetorical discourse focusing of Lhoyd Bitzer's concept of the rhetorical situation. The one thing lacking in establishing a true rhetorical situation in Bitzer's sense is the presence of "specific persons" the speaker is addressing.

Linking e-portfolios to social software makes the creation of the e-portfolio a personal issue - you are talking to your contacts/friends. The article concludes by exhibiting an example of 
a double programme as described above on a programme for Multimedia Designers at LILLEBAELT Academy of Professional Higher Education.

\section{Introduction}

Self-representation is becoming a prerequisite for success in modern life. Professionals have to be able to "show and tell" their competences, and make them plausible by showing examples of their own work. When students are training to obtain a set of competences, they are asked to demonstrate them at the same time as acquiring them. See for example the following introduction to an online jobnet for recent graduates: "Why should you consider an online portfolio? Because the online portfolio, your professional web site, enables you to "show and tell" employers that you have the right mix of skills and qualities for the job by showcasing your work."1

Self-representation is often done through the medium of a portfolio, which in schools and universities is being developed as part of the curriculum. An e-portfolio is a digital profile showing a collection of diverse evidence (texts, images, video clips etc.) created in authentic activity. It is brought together and recontextualized to say something about what the student knows and can do (or how he/she has grown or changed). ${ }^{2}$

At the same time, a whole generation of youngsters is creating digital self-representing content, voluntarily, in social software environments like Facebook and MySpace. This content is seldom linked to the practises of self-representation in schools - and has more to do with creating selfimage than with displaying learning.

It has become an everyday part of life for many young Danes to portray themselves online. According to figures from Facebook (May 2008), there are 427,740 Danish Facebook members between the ages of 18 and 30. This is the age group to which the majority of students belong. In total there are 820,282 Danes (Statistics Denmark/May 2008) in that age group, which means that $52.1 \%$ of young Danes are registered with a Facebook profile. This represents more than half of the age group, and the figure is rising. In December 2007 the number of Danes between the ages of 18 and 30 with a Facebook profile was 242,220, which means that in the course of four months the number of Danes between the ages of 18 and 30 with a Facebook profile rose by no less than $76 \%{ }^{3}$

It is hard for an educational institution to ignore these figures when it offers its students an e-portfolio as a learning tool. When being introduced to learning e-portfolios a new student may find it strange to be asked to make one, when he or she has already created a digital profile in social software such as Facebook or Linkedln. They may very well feel that the teachers are asking them for a repeat performance.

Are institutions of higher education in danger of boring students with obsolete technology, like in the mid-70s when it was years before Denmark's high school students were allowed to use pocket calculators instead of slide rules? Can the educational objectives of the use of e-portfolios be realized in Facebook or other comparable social software platforms - or does the social software obstruct the objectives that educational programs promote in using e-portfolios? Is there a beneficial way of using social media to create educational e-portfolios? 


\section{The difference between the communicative context of an e-portfolio and of a profile in social software}

There are a number of areas where the two representation forums (the learning e-portfolios and the profile in social software) could be seen as incompatible. As indicated above the learning eportfolio is part of the curriculum. Every student creates his or her own - but only because they are asked to do so by their teachers. The content of the e-portfolios is created and owned by the student, but the structure and type of content is based on educational requirements.

A Facebook profile is personal as well, even though the structure and type of content is limited to what the social software will allow (e.g. uploading of images, micro blogging). Once you own a profile it is comparable with other profiles in the ways the software decides. Your picture has the same position and size as everybody else's, but it is unquestionably your own. In the creation of an e-portfolio the student is often allowed to visually design the surface in his/her own way, whereas a profile in social software offers little or no possibility of doing this. ${ }^{4}$

The creation of the social software profile is sometimes done for recreational purposes, sometimes for professional reasons - whereas the creation of an e-portfolio is often part of curricula work (for students). The goal of the e-portfolio is professional (demonstration of competences) whereas the goal of the profile in social software can be anything from meeting friends to being seen in a professional context.

This article compares the two modes of self presentation based on the e-portfolio practice on the Multimedia Programme (MMD) at LILLEBAELT Academy of Professional Higher Education, Odense Denmark. Since 2004, 635 students have created an online e-portfolio based on an open source CMS (content management system). ${ }^{5}$

On the MMD programme a little over half of the students are women (322 of the 635 e-portfolios). The average age when starting the programme is $21 .^{6}$ This is a typical MMD e-portfolio belonging to a graduate student, Camilla, (who is a woman and was 21 when she started.) ${ }^{7}$

The course has three objectives with the e-portfolio ${ }^{8}$ : firstly, it forces the student to reveal his/her communication skills in relation to a chosen target group; secondly, it allows the student, through reflection, to demonstrate his/her own competencies by having to display and describe them according to a set structure; and finally, the e-portfolio is seen as a way of qualifying observations of one's own learning by having to tell about them in a professional forum.

This article will firstly compare the social software profile of an MMD student with her online portfolio to see if the objectives listed above could be met as well in the social software as in the online portfolio. The article will especially explore whether or not the e-portfolio or the Facebook profile show signs of a high level of communication skills, which in the assessment of the rubric is described as engaged in a rhetorical discourse. Secondly, having analysed this, the article will look at what other benefits social software has in relation to learning. Thirdly it will suggest a strategy of self-representation in learning environments where learning portfolios are combined with social software to enable the student to establish relations and to gain knowledge of his or her own competences in creating and maintaining (professional) relations. 


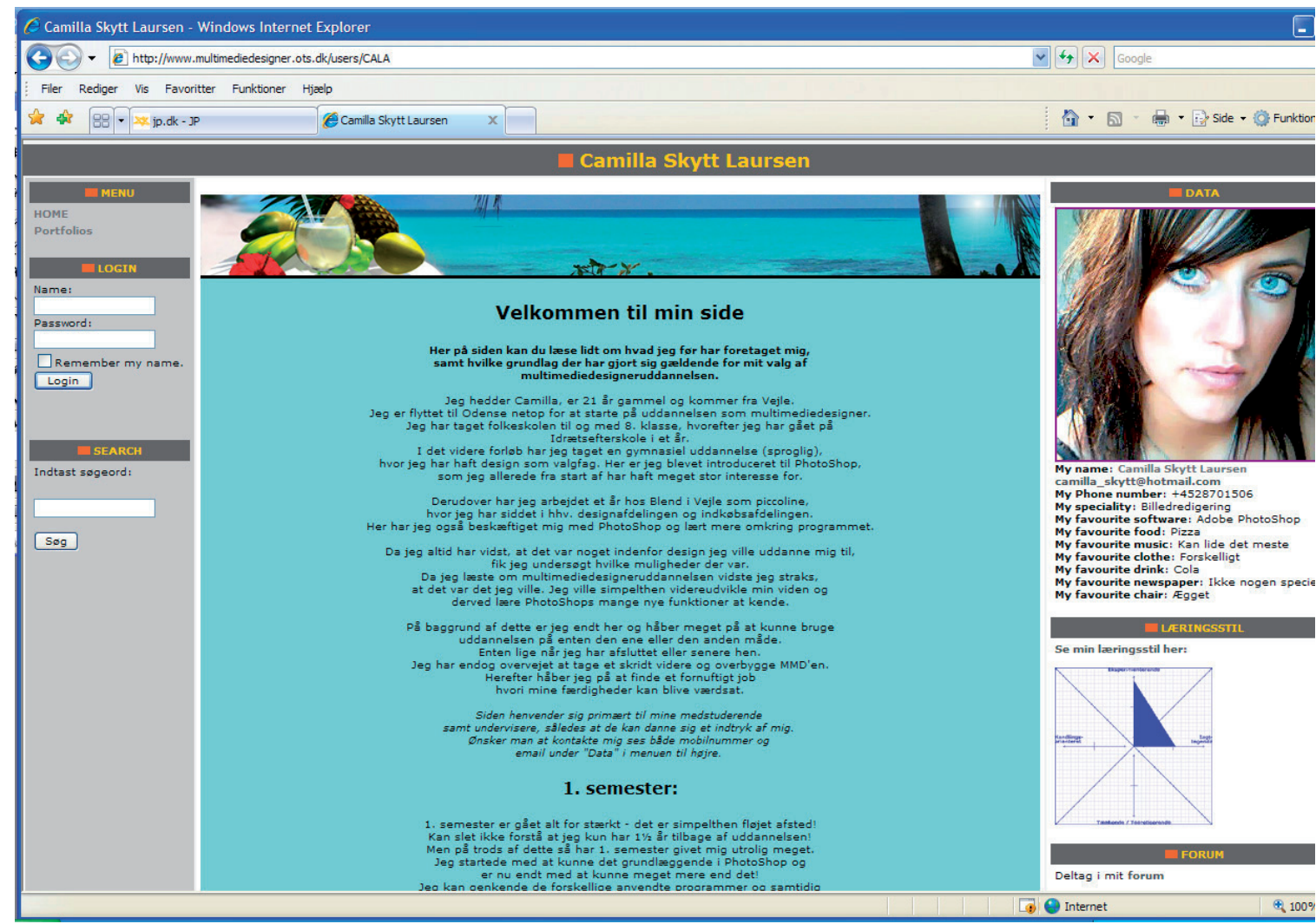

\section{The rhetorical situation of the e-portfolio}

In order to help the students meet the objectives mentioned above an assessment rubric and a description of mandatory content has been developed on the MMD programme. This is used to grade the e-portfolios. In the MMD description of "Mandatory Content in 1. semester Portfolio" the demands for the front page of the e-portfolio are described as follows: This is the place where the student explains his or her intentions with choosing Multimediadesigner - and the goals he or she hopes to achieve by finishing this course. In the "Multimediadesigner, First semester, Evaluation criteria"10 this content is evaluated in accordance with the following criteria: Goals and objectives are clearly and concisely written, and later: The student addresses explicitly her target groups. The portfolio invites and publishes comments.

What is looked for in assessing communicative competence is the student's competence in addressing and acknowledging an audience - and doing this in a clear and concise way. We are in other words, asking them to acknowledge that the writing (and designing) of the e-portfolio is to participate in a rhetorical discourse. They are trying to persuade their readers that they are competent as Multimedia Designers.

This notion of communicative competence is based on an understanding of what Lloyd Bitzer describes as a rhetorical situation. Bitzer describes the rhetorical situation as "those contexts in which speakers or writers create rhetorical discourse" (Bitzer 1965: 1). 
Bitzer goes on to describe rhetoric as "(...) the creation of discourse which changes reality through the mediation of thought and action" (Bitzer 1965: 4). When the objectives are as described above, the e-portfolio seems to want to do exactly that: create a discourse which mediates between thought and action. We want our students to become aware of and demonstrate their competences through the e-portfolio to potential audiences.

The question which could be asked both of an e-portfolio on MMD and a social software profile is whether or not a rhetorical situation in this sense is actually acknowledged in both situations. According to Bitzer, a rhetorical situation exists where there is "a complex of persons, events, objects and relations presenting an actual or potential exigence which can be completely or partially removed if discourse, introduced into the situation, can so constrain human decision or action as to bring about the significant modification of the exigence." (Bitzer 1965:4)

A vital term here is exigence, defined by Bitzer as "an imperfection marked by urgency". Bitzer points to the fact that in rhetorical discourse you want to right a wrong. The e-portfolios on MMD have to bear witness of exigence for the students in the following way: We want them to acknowledge the rhetorical situation - and the shear fact that the e-portfolios are online is meant as an incentive - they are already addressing the internet audience as such. To acknowledge the rhetorical situation of the e-portfolio we ask them to verbalize the people they are addressing and the event (and object) of the portfolio itself. We want them to turn the demand to create an e-portfolio into a situation, where they are trying to persuade their audience of their competences. It should be urgent for them to convince their readers, who prior to reading have no knowledge of the students and their skills.

In her MMD e-portfolio Camilla starts as follows: "Welcome to my page. Here on this page you can read a little about what I did before, as well as my reasons for choosing the multimedia education (author's translation)." Here she acknowledges the special communicative situation and helps the audience to understand what the purpose is. She does not on the other hand address a particular audience as another student does in her e-portfolio: "Hello dear colleague, my name is XXX. I was born and spent all my life in Lithuania" - because this student speaks to an unknown colleague. However, she is not very specific regarding what she wants the "colleague" to gain from reading, and thus tries particularly hard to persuade. A third student on the other hand acknowledges a full rhetorical situation when she writes: "This e-portfolio is intended to be a place for my self-evaluation about my studies on MMD. It contains my results, thoughts and feelings as well. This helps my teachers to get quicker feedback and me to share my experiences with my fellow students more effectively than in face to face chats during the lunch breaks or at parties."

\section{Exigence in Facebook}

So what about a Facebook profile of a student? The profile must be the result of some sort of urgency for the student, as he or she creates them quite voluntarily. Can they be seen as rhetorical discourse in Bitzer's sense?

To look at the Facebook profile of Camilla1 ${ }^{11}$ you have to log in to Facebook. You cannot read a 


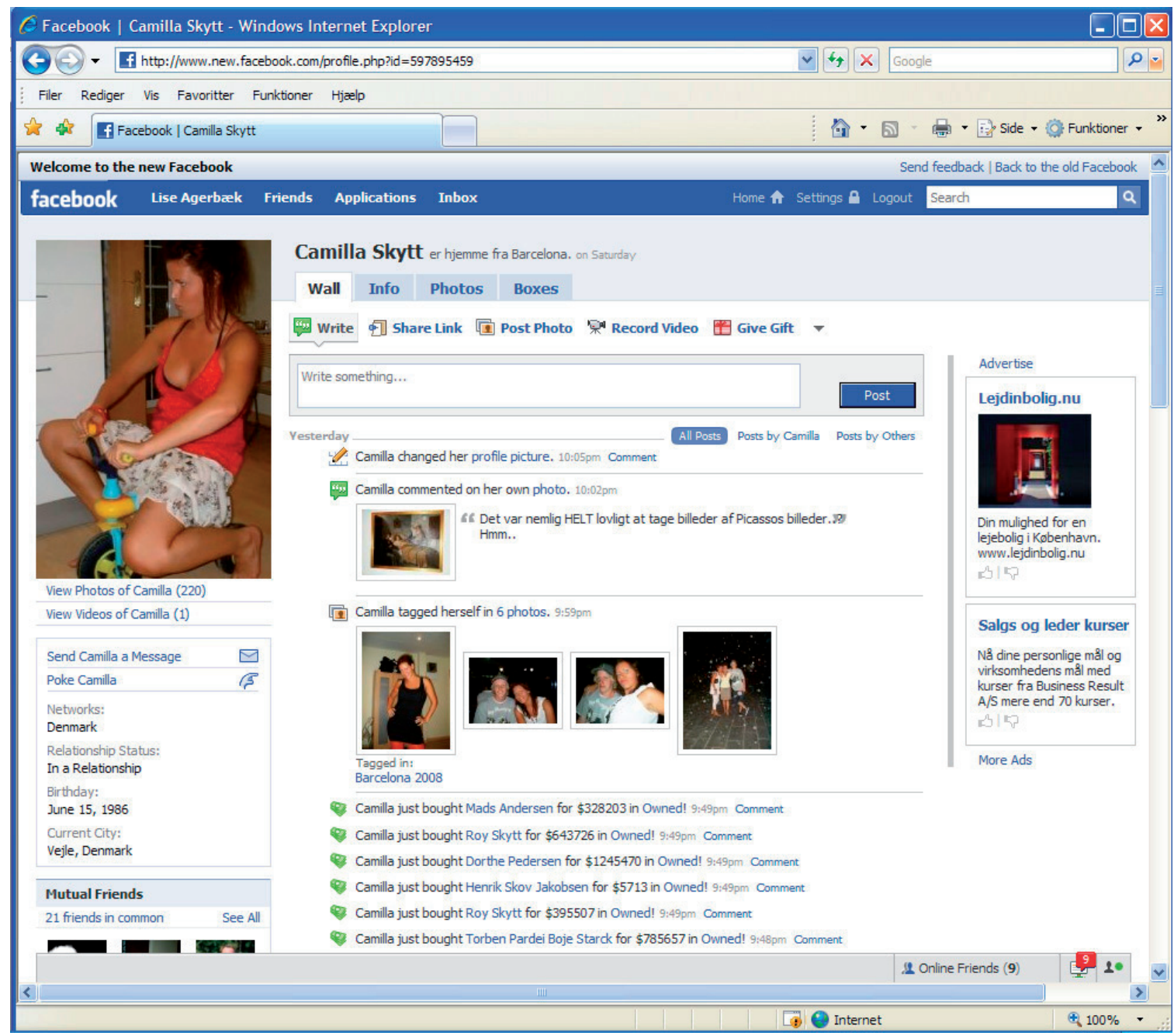

Facebook profile without being a member yourself. In this way the potential audience is reduced compared to the MMD e-portfolio. But once you are logged in the audience is clearly defined - you speak to whomever you have accepted as your "friend" in the Facebook sense of the word. Camilla has (presently) 306 friends. Thus, her target group is very well defined. She has made an extra effort to establish relations with each and every one.

Once it is open you meet her profile. The profile is structured in the same way as all Facebook profiles. Camilla's picture and links to friends and photos are placed on the left side of the screen, Camilla's "Wall" displaying recent actions Camilla carried out in Facebook, in the middle and advertising on the right hand side of the screen.

Camilla has not used the free text just below the image to address her audience directly. She has chosen to write an "update" - a description of what she is doing right now, which is limited in length. This changes whenever Camilla writes something new - which in Camilla's case is quite often. The rest of the communication could be said to be done indirectly, through the nature of the profile picture and the list of Facebook applications that Camilla has recently participated in. 
On this particular day, she is presenting herself with a picture where she is sitting on a bike made for toddlers, and you can read that she has "bought"12 a lot of friends. None of this gives a particularly clear message. If you look at Camilla's Facebook profile, it does not allow for a rhetorical situation in Bitzer's sense. It does present "a complex of persons, events, objects and relations", but not a possibility for a clear discourse to create the persuasion.

But if we look further into the rhetorical vocabulary it could be argued that the "update" creates a certain persuasio - or effect on the reader. At the very least it shows that Camilla is present and alert, and what her state of mind is. Maybe it also shows that she has a sense of humour.

\section{Exigence in Linkedln}

If we turn to another kind of social software, Linkedln, the possibilities are more or less the same ${ }^{13}$ as in Facebook. You create a profile and link to what Linkedln defines as contacts. The difference to Facebook is that Linkedln defines itself as a professional network: "Linkedln is an online network of more than 19 million experienced professionals from around the world, representing 150 industries",14 as they write. LinkedIn has professional objectives and requires users to accept all their relations - the same way each user must be accepted in order to gain admittance to others' networks. In return, Linkedln makes it possible to look for jobs or for employees - and you can give and receive recommendations (very often work related).

In Camilla's Linkedln profile she presents herself a lot more quietly. She describes herself as a student, and describes her exchange student experiences, but she does not display a picture of herself.

This profile seems to have a different message, but it still doesn't allow for a clear discourse. The message has to be read from the information, Camilla supplies - not from a direct message

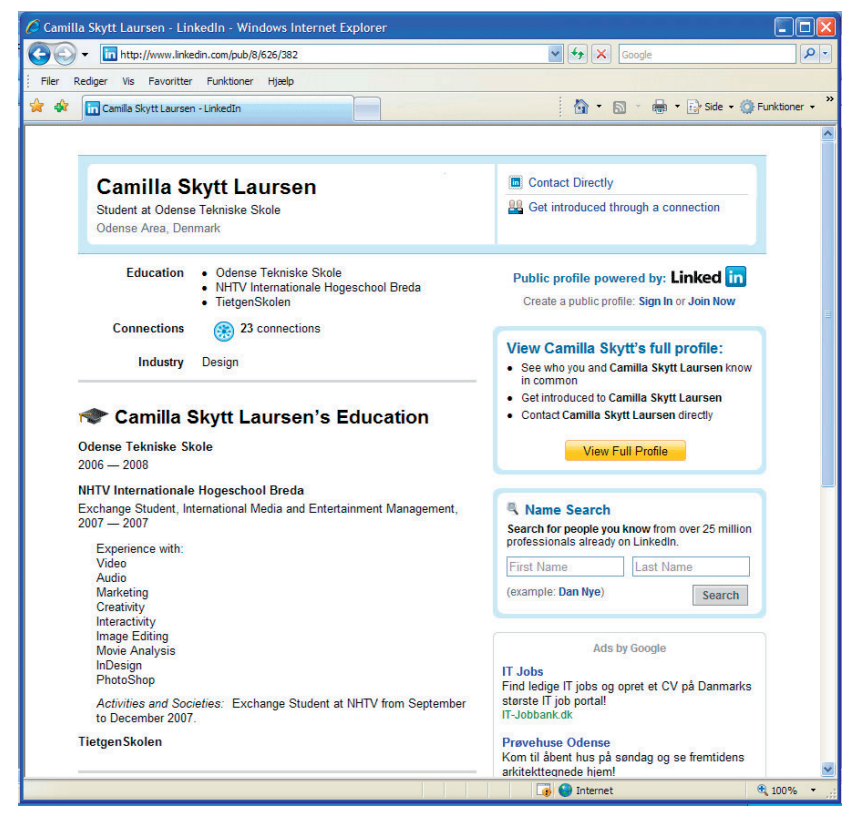
targeted at the reader. Linkedln shares with Facebook the very clear definition of the readers as Camilla's "connections" - people who in Linkedln have accepted a relation to Camilla.

\section{Comparing e-portfolio presentations with profiles}

As shown in the above examples the rhetorical situation of the e-portfolio is not acknowledged in every one. This could be seen as being due to the fact that the e-portfolio is not the result of an exigence that is experienced by the student. As a learning institution, we force it upon 
them - thus creating an artificial situation in which the students have no choice but to respond (if they want to get a good grade and pass an exam). Thus only some respond as we hope (the third student being an example). She creates her own exigence from the one we stipulate.

As with Camilla many of our students create non-rhetorical discourse in their e-portfolios. In order to become a rhetorical discourse, it must "produce action or change in the world" (Bitzer 1965: 4). The e-portfolio is in this regard a very special rhetorical situation because the change or action brought about by the e-portfolio happens to the writer him or herself. The recontextualizing of the evidence of authentic work (the e-portfolio) bears witness to the writer's learning - so that the e-portfolio is both proof and a presentation of the author's development at the same time.

Neither the Facebook nor the LinkedIn profile allows for direct address from the owner to his or her audience. Microblogging is possible, but it is generally too short to warrant an argument.

\section{Presenting awareness of own learning in the e-portfolios}

The third purpose of the use of e-portfolio on MMD was, as mentioned above, to use them as a way of qualifying observations of one's own learning by having to tell about it in a professional forum. We have this objective, because the competences students on MMD can hope to gain through the MMD program have to be generic as well as "hard skills" (programming, image manipulating or the like). The problem is that the knowledge of programming languages and file formats, etc., needed in the current multimedia changes rapidly because of the nature of the industry. The coding languages that we teach our student can already be obsolete 6 months after a student has graduated. It is therefore particularly important for our students to show that they are good learners. Once they are hired by companies they have to be able to learn new coding languages by themselves.

In the MMD description of "Mandatory Content in 1. semester Portfolio"15 the demands for the descriptions of the 4 subject areas in the e-portfolio are described as follows: On the front page of this profile the student tells of his and her progression within this subject during the 1. semester. How much did you know at the start of the semester? What have you learned? In the "Multimedia designer, First semester, Evaluation criteria"16 this content is evaluated in accordance with the following criteria: Overall description of the learning process (project work, group work, individual work). Here the student writes how he or she has experienced learning on $M M D$, and later: Understanding of the processes and their impact on own learning is clearly and concisely written.

To write about your learning, you have to create discourse. This presupposes a possibility for a direct application from the author to the reader. And for the purpose of the e-portfolio on MMD to be fulfilled the students need to create not only discourse, but also rhetorical discourse. The rhetorical discourse is necessary because the students have to convince (persuasio) their readers that they are good learners. In the e-portfolios we make the students create our premise is that they can make their learning competences plausible through describing and documenting their learning. This premise is often argued in the e-portfolio literature (Ellmin 2000: 32), (Lund 2008: 33) or (Qvortrup 2006: 94).

Thus, in this sense Facebook or Linkedln cannot replace the e-portfolio because they do not allow for a direct application to the reader from the profile author. 


\section{But can the social software supplement the e-portfolio?}

In its current form, however, our e-portfolio has been difficult to use in fulfilling another objective, which is to get the students to view their social competencies - their ability to create a network - as a professional resource. As demonstrated above our students find it difficult to direct their e-portfolios at a specific target group. Only a few manage to create a true rhetorical situation in Bitzer's sense. Within the context of the e-portfolio the students are given a complex of events, objects and relations - but these are not established in the presence of specific persons. Maybe this is the reason why relatively few students experience an actual or potential exigence - which would provoke a discourse, which would potentially constrain human decision or action as to bring about the significant modification of the exigence, to quote Bitzer again.

The social software environments, on the other hand, do exactly this. The students, who have Facebook or Linkedln profiles, establish relations with particular people. These people have to accept the relation - or it does not come into existence. As mentioned above this creates a more acute communication situation for the students- an exigence. They talk to people with whom they have established clear connections, often based on "real life" connections. Your target group in Facebook or LinkedIn is people you know instead of the more blurred and opaque target group "the internet audience".

\section{A double strategy}

On MMD we have for these reasons decided to ask our graduates to establish a Linkedln profile. We have chosen to use Linkedln because it is a professional network. We gather the students together in a special Linkedln group.

\section{My Groups}

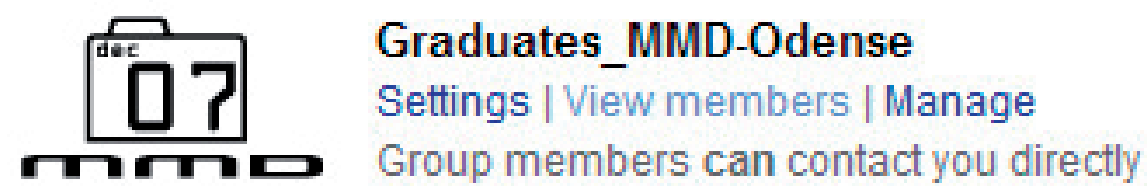

There are several obvious advantages: The coupling/linking makes the students' relations appear as part of their visible competencies - in other words, a student with a "cool" network appears more professional than one without a "cool" network. The student is therefore forced to present him/ herself in relation to others and hopefully be encouraged to qualify his/her network by establishing more and more professional relationships with people within the industry. They link to their learning e-portfolios - thus having an incentive to show their learning competences in a professional way. 
Our experience shows that far more students gain employment via their networks - and often get jobs with each other. Our students start up their own companies and hire each other because they know and trust the competencies gained through their common educational background. However, they do not often realize the significance of these relations while they are studying. It's only after they have graduated and are unemployed that they start looking at their network. ${ }^{17}$

\section{Facebook is not professional}

We rejected Facebook because it is based on personal rather than professional relations. Characteristically, a network on Facebook consists of "friends" whereas on Linkedln the network consists of "contacts." Facebook is also often used to show private pictures of oneself and others in more or less embarrassing situations. You cannot be sure that undesirable photos of yourself won't surface on someone else's profile if they are "tagged" by other users. It is possible to remove this tagging, but it means that you have to keep a constant eye on Facebook.

It is also more demanding to link the e-portfolio to Facebook. When you create a profile you are not asked to link to more than one other resource - that could be, for example, an e-portfolio. It is possible to link pages to a profile where you can write your reflections, but that is not the way Facebook is used today.

The most important aim of using e-portfolio to strengthen the learning process is, however, that it forces the student to reflect upon the learning process. To reflect oneself in words and images in relation to developing oneself and one's skills - this focus is in danger of disappearing in Facebook's jumble of film quizzes, person buying and party photographs. This is the reason Facebook is not currently being considered as a relation resource for the e-porfolios on MMD.

The close connection between the social software and the e-portfolio is important, because we need to be sure that the student acknowledges and understand the connection for the student to experience the exigence - an urgency to show and document learning competences. In Linkedln it is an integrated part of your profile that you link to external resources.

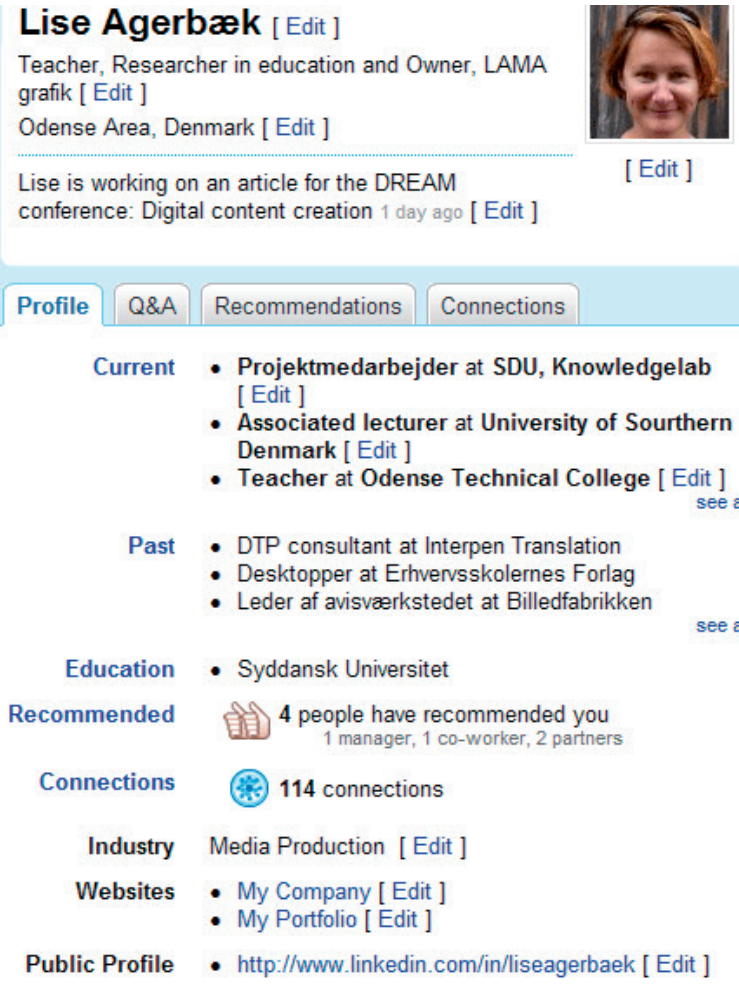

- Associated lecturer at University of Sourthern Denmark [ Edit ]

- Teacher at Odense Technical College [ Edit ]

Past - DTP consultant at Interpen Translation

- Desktopper at Erhvervsskolernes Forlag

- Leder af avisværkstedet at Billedfabrikken

Education

Recommended

- Syddansk Universitet

Connections 114 connections

Industry Media Production [ Edit ]

Websites - My Company [ Edit ]

- My Portfolio [ Edit ]

Public Profile • http://www.linkedin.com/in/liseagerbaek [ Edit ] 


\section{Conclusion}

It is a good idea to combine e-portfolios with social software because the combination forces the owner of the e-portfolio to address a particular target group (the people they have accepted as contacts).

In this article I have analyzed the communicative competences we demand from our students and connected them to a rhetorical perspective. The e-portfolios could be seen as a particular sort of communication, as rhetorical discourse, because the students are trying to convince their readers of their competences. For our students to experience an exigence in relation to writing about their learning, it is an incentive that they are up, close and personal with their target audience.

It is our experience that they do not feel this when filling out the e-portfolio by itself. The social software offers an opportunity for the student to know their target audience because you as a user create relationships as an agreement between two parties: the profile owner and the contact.

At the same time new students develop their social competences because the social software creates a situation where they have to contact people and establish relationships with them. This is often a prerequisite for getting a job.

\section{References}

Perelman, C. and Olbrechts-Tyteca, L. (1969). The new rhetoric: A treatise on argumentation. (J. Wilkinson and P. Weaver, Trans.). Notre Dame: University of Notre Dame Press.

Bitzer, Lhoyd (1965) The rhetorical Situation http://www.samford.edu/Rhetorical_Situation_Bitzer.pdf (downloaded July 31 2008).

Lund, Birthe (2008) "Læringsteoretiske begrundelser for portfolien som pædagogisk redskab i en skandinavisk tradition" in Portfolio i et laerings- og uddannelsesperspektiv ed. Birthe Lund, Aalborg Universitetsforlag.

Qvortrup, Lars (2006) Knowledge, Education and Learning: E-learning in the Knowledge Society, Samfundslitteratur. Ellmin, Roger (2000) Portfoliomodellen, Gyldendal Uddannelse.

\section{Notes}

1. http://www.jobweb.com/Resume/help.aspx?id=794 (downloaded March 12, 2009).

2. This definition is based on a definition presented by Darren Cambridge (an acknowledged e-portfolio scholar at George Mason University, Virginia, USA) at an online seminar for the TLT group in May 2008.

3. January $200934 \%$ of all Danes have a Facebook profile (http://www.news24.com/News24/Technology/ News/0,2-13-1443_2459162,00.html) downloaded March 14, 2009.

4. In Facebook profiles are visually designed by the platform owners. In MySpace it is possible to design backgrounds and choose colour palettes etc.

5. See http://www.multimediedesigner.ots.dk/

6. A recent survey of the students shows these numbers.

7. Camilla has given her permission to use her portfolio and her profile in this article. 
8. Based on an interview with Head of Staff Ida Borch performed April 2008.

9. This description is given to the students at the start of 1. semester. See http://www.multimediedesigner.ots. $\mathrm{dk} /$ referater/KravPortfolio1sem_UK.doc

10. See http://www.multimediedesigner.ots.dk/referater/Portfolioevaluationcriterialnnovation.doc

11. http://www.new.facebook.com/profile.php?id=597895459 Camilla has given her permission to use her profile.

12. You can fictively buy and sell friend in a Facebook application called "Owned".

13. A Linkedln profile can be read without login - but its main raison d'etre is to establish and maintain relations.

14. http://www.linkedin.com/static?key=company_info

15. This description is given to the students at the beginning of 1. semester. See http://www.multimediedesigner. ots.dk/referater/KravPortfolio1sem_UK.doc

16. See http://www.multimediedesigner.ots.dk/referater/Portfolioevaluationcriterialnnovation.doc

17. A further advantage is that the Linkedln group also keeps us connected to our students after they have graduated. They must maintain their profile and this suddenly gives us access to updated e-mail addresses, telephone numbers, job information, etc. In a wider perspective, the students' e-portfolios are no longer just a part of their education, but have become part of their existence. 